\title{
Fire Risk Assessment for Piping System of LCT CNG Carrier
}

\author{
Munir Muradi ${ }^{1, a, *}$ and Bina Aji Nugraha ${ }^{2, b}$ \\ ${ }^{1}$ Research and Technical Development Biro Klasifikasi Indonesia, Jakarta, Indonesia \\ ${ }^{2}$ Inspectorate General, Ministry of Maritime Affairs and Fisheries, Jakarta, Indonesia \\ a.munir.m@bki.co.id,b.bina.aji@gmail.com \\ *corresponding author
}

Keywords: $\quad$ CNG, Conversion, Fire Risk, LCT, Piping System, Gas Release.

Abstract: Utilization of Natural Gas as a source of electrical energy is supported by the increasing of world electricity demand, especially Indonesia. Indonesia's geographical conditions, as archipelago country, provide challenges in the distribution of natural gas throughout the region. The distribution of gas from the gas source to the plant site requires an effective, efficient, and safe CNG Carrier. Some Landing Craft Tank (LCT) in Indonesia that is currently not functioned properly bring the idea to be utilized as one of the right choices as a CNG carrier. For conversion of LCT to CNG carrier must keep priority on safety aspect such as in the storage piping system. The piping system is highly vulnerable to explosion hazards caused by gas leaked. The released gas causes the piping system to have potential risks that need to be minimized. The fire risk assessment method is conducted under the BKI Reference Notes of Risk Assessment Applications for the Marine and Offshore Oil and Gas Industries, where the hazard identification is performed by using HAZOP (Hazard Operability). The HAZOP is performed by dividing the systems into several sub-systems. Released gas frequency is analysed using Fault Tree Analysis (FTA). As well as the accident analysis frequency of occurrence which will be scripted stage that gas released as the last order due to the malfunction order. Gas released near ignition source may lead to Flash Fire, Gas Dispersion and Gas Explosion. Using Event Tree Analysis (ETA) the frequency of occurrence will be calculated according to the impacts. Consequence analysis is then performed using the fire spread software. To represent the risk, F-N curve is used to determine the acceptance criteria classified into three conditions such as tolerable, in-tolerable and As Low as Reasonably Practicable (ALARP). The results obtained from this research are divided into two conditions is immediate ignition and nonimmediate ignition. in immediate ignition conditions, the risks are flash fire and gas explosion but in tolerable levels of risk. In Non-immediate ignition conditions, the risk is Flash Fire and Gas Dispersion in tolerable level of risk and non-immediate ignition conditions, gas explosion in ALARP level. The ALARP condition to be still at a safe level but some things of concern must be taken to cope or reduce the severity of the impact of the gas explosion. In ensuring the safety of the installation high pressure pipe CNG mounted it is necessary to note the safety provisions for the type of ship carrying gas above the deck including the hazardous area (cargo containment arrangement). 


\section{Introduction}

World Factbook announced the amount of World Natural Gas Resources is around 197.4 trillion cubic meters. Indonesia has 2.77 trillion cubic meters of natural gas resources that is number 14th in the world [1]. Nowadays, the utilization of natural gas has been recognized as energy resources. Some power plant installations have been built using natural gas as the resources. There are some natural gas types, such as Compressed Natural Gas (CNG) and Liquefied Natural Gas (LNG). CNG is cheaper than other conventional fuel [2]. CNG can be used directly as energy resources which does not need regasification unit. Usually, CNG production unit and the power plant are built in different places that allows the stakeholders to make more effort to transfer the CNG. CNG carrier and pipeline installation can be two of the choices. However, the pipeline installation has some limitations on distance. It can be used when the power plant is near the production unit. CNG carrier has some flexibilities to transport the CNG. There are plenty Landing Craft Tank (LCT) which has been laid up. Therefore, some industries in Indonesia propose utilization of LCT to transport the CNG. CNG carrier has strict requirements in Oil and Gas Industry. It is a new developing technology. Some requirements have been made to convert the CNG Carrier.

The mechanism of LCT CNG carrier is similar as CNG Bus Carrier, the CNG was putted in a storage tank then putted on deck. The difference is in the safety of installations installed on board vessels. many things to be considered in the laying of tanks and safeguard systems on board, should pay more attention to the hazardous area. There are storage piping systems that connect each tank to loading/ unloading manifold. The piping storage systems comprise valve and pipeline. The CNG conditions in the tank shall be maintained against excessive pressure and excess tank temperature.

$\mathrm{CNG}$ is a flammable material. CNG may lead on fire and explosion damages. Fire damage can be caused by gas release and fire ignition source. Meanwhile explosion damage can be caused by overpressure such as gas loading over the capacity. Therefore, the risk assessment may be analysed to prevent fatal damage to vessel and crews. The CNG tank need some safety constructions to protect the tank from any impacts and maintain the tanks in position. Despite the safety construction, the CNG storage piping system is also need safety devices to prevent the gas release and also the explosion. In order to check the risk level of the storage piping system and give the mitigation to reduce the risk, fire risk assessment is analysed based on BKI Reference note of Risk Assessment Application for The Marine and Offshore Oil and Gas Industries [3].

\section{Risk Assessment Methodology}

\subsection{Risk Assessment}

The risk assessment focuses on the fire risk of storage piping system. The method that is used for the fire risk assessment is described in Figure 1.

The fire risk assessment is analysed using BKI Risk Assessment Application for the Marine and Offshore Oil and Gas Industries. The hazard is identified using Hazard Operability (HAZOP). In identifying the hazard, the storage piping system is divided into some subsystems. Based on the subsystems hazard identification, the frequency of hazard is analysed according to Fault Tree Analysis (FTA). The root source of risk is component failure (valve blockage) which lead overpressure, gas leakage, and then gas release. The frequency probabilities of each hazard are calculated using Event Tree Analysis (ETA). The consequence of gas release is analysed using fire spread software. From the simulation results will be generated the impacts due to gas release such as flash fire, gas explosion and gas dispersion. And then, the risk evaluation is represented by the F$\mathrm{N}$ curve UK HSE Offshore [4]. From the result of risk evaluation steps, the level of risk 
consequence can be obtained with three categories is tolerable, in-tolerable or ALARP level. If the result of risk representation is ALARP level, mitigation can be done to reduce the risk level.

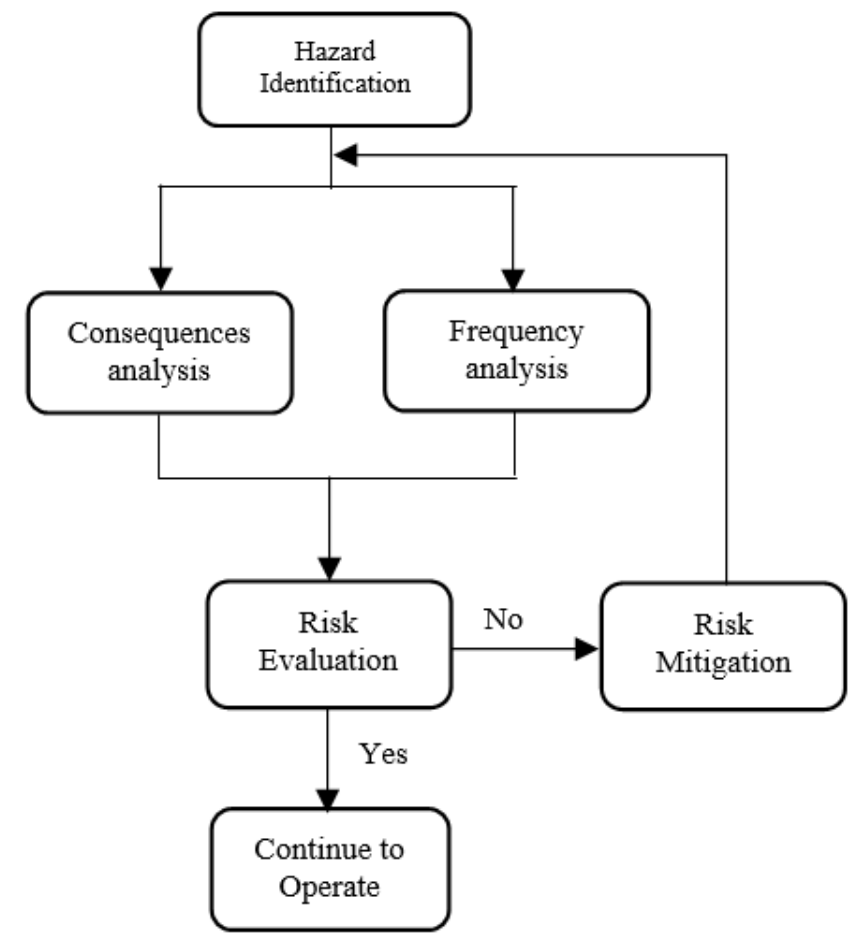

Figure 1: Risk Assessment Workflow.

\subsection{Hazard Identification}

Identification by distribution of subsystem known by the division of the node [5], make it easier to analyse the identified system. Hazard Identification is used for analysing the potential risk from a systematically process of storage piping system (P\&ID) (see Figure 2). In identification, the analysed system based on figure 2 is divided into several parts of sub-systems and then a team evaluating using brainstorming or assisted by a set of checklists. Description of High-pressure storage can be seen Table 1.

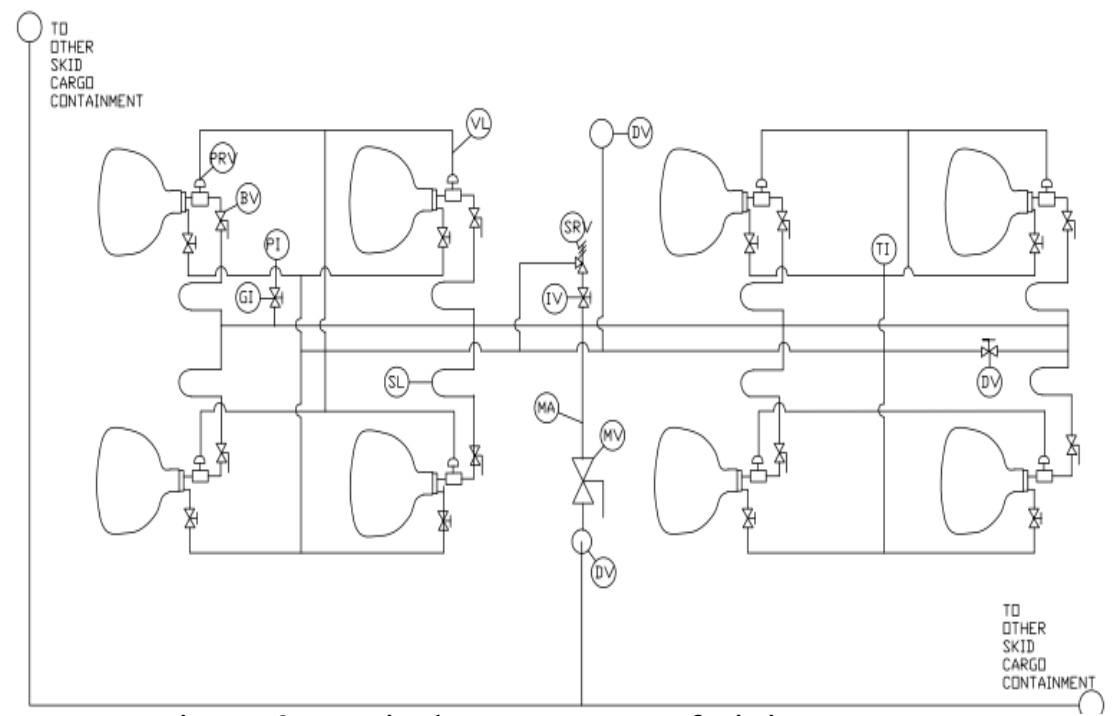

Figure 2: Typical PID System of Piping Storage 
Table 1: Node/ SUB-SYSTEM

\begin{tabular}{|c|c|l|}
\hline No & \multicolumn{1}{|c|}{ Node } & \multicolumn{1}{|c|}{ Description } \\
\hline 1 & High Pressure Pipe & $\begin{array}{l}\text { is a cargo containment system supported by a complex } \\
\text { security installation, including for loading/ unloading } \\
\text { needs. CNG tank skid consists of 12 skid tanks, but the } \\
\text { object of research here only on skid tank no.1 }\end{array}$ \\
\hline
\end{tabular}

The hazard is identified according to Hazard Operability (HAZOP) of British Standard IEC 61882:2001 [5]. The result of the following hazard identification for Ball Valve (BV) is shown in Table 2.

Table 2: Hazard Operability

\begin{tabular}{|c|c|c|c|c|}
\hline \multicolumn{2}{|c|}{ Study Title } & \multicolumn{3}{|c|}{ LCT CNG Carrier } \\
\hline Drawing 1 & $=$ & \multicolumn{3}{|c|}{$\begin{array}{ll}\text { Dwg. No.Xxx-KI } & \text { Node }: 1 \\
\end{array}$} \\
\hline \multicolumn{2}{|c|}{ Part Considered } & \multicolumn{3}{|c|}{ Piping Storage System (CNG Container Skid No. 1) } \\
\hline \multicolumn{5}{|c|}{ Design Intent: } \\
\hline \multicolumn{5}{|c|}{ Source: } \\
\hline $\begin{array}{l}\text { 1. Ball Va } \\
\text { 2. Pressur } \\
\text { 08) } \\
\text { 3. Drain V } \\
\text { 4. Master } \\
\text { 5. Manifol } \\
\text { 6. Temper }\end{array}$ & $\begin{array}{l}\mathrm{V}-01 \sim \mathrm{D} \\
\text { MV-01) } \\
\text { ably } \\
\text { luge (TG- }\end{array}$ & $\begin{array}{l}\text { V) } \\
\text { V-01 }\end{array}$ & $\begin{array}{l}\text { 7. Pressure Gauge (PG-01 } \\
\text { 8. Gauge Isolation Valve } \\
\text { 9. Supply Loop (1 Set) } \\
\text { 10. Vent Line (1 Set) } \\
\text { 11. Safety Relief Valve ( } \\
\text { 12. Flange Set/ Packing S }\end{array}$ & $\begin{array}{l}\text { GIV-01) } \\
\text { RV-01) } \\
\text { eal (1 Set) }\end{array}$ \\
\hline No & Dev. & Source & Possible Causes & Consequences \\
\hline \multirow{5}{*}{1.} & No flow & $\mathrm{BV}-01$ & $\begin{array}{l}\text { Wear of the elastomer } \\
\text { and/or seat seals over } \\
\text { time, foreign or abrasive }\end{array}$ & $\begin{array}{l}\text { Overpressure on pipe, } \\
\text { if pipe rupture gas } \\
\text { release leads to Gas } \\
\text { Dispersion and jet fire, } \\
\text { flash fire if any source } \\
\text { of fire }\end{array}$ \\
\hline & No flow & BV-02 & $\begin{array}{l}\text { Corrosion in the } \\
\text { pipeline, incorrect ass. }\end{array}$ & Overpressure on pipe, \\
\hline & Dev. & Source & Safeguards & Recommendations \\
\hline & No flow & BV-01 & transmitter/ & $\begin{array}{l}\text { 1. Seal on the flange } \\
\text { must be rigid } \\
\text { 2. Seal on the flange } \\
\text { must be insulated }\end{array}$ \\
\hline & & BV-02 & & $\begin{array}{l}\text { 3. Provide automatic } \\
\text { cut off valves for } \\
\text { line leaks (ESD) }\end{array}$ \\
\hline
\end{tabular}

From Table II, the HAZOP is the Qualitative Method of Fire Risk Assessment. The hazard from the HAZOP is identified as failure of component.

Failure of component in CNG tank may lead the gas leaked and released to the air. The Gas Release when no fire ignition may lead a gas dispersion hazard. It is spread to the air and smelled for a while. On the other hand, if the Gas Release is near the fire ignition source, it will lead the 
minor damage to the near environment such as jet fire and flash fire. The fire spread area should be estimated to prevent any danger among the crews. The major damage may lead the gas explosion, which can cause death. The explosion may happen when high pressure impacts the CNG tank.

\subsection{Frequency Analysis}

Frequency analysis is a method to determine the frequency probabilities of identified hazard. There are two methods in determining the frequency assessment, Historical Data Analysis and Tree Analysis. In determining the frequency assessment, the Tree Analysis is used. There are two phases in the analysis, which are Fault Tree Analysis (FTA) and Event Tree Analysis (ETA). The FTA is used for determining the frequency probability of the gas release hazard. The FTA is a method in evaluating the failure using logical gates to connect an event to another event in the system based on the scenario failure of system can be seen in Figure 3.

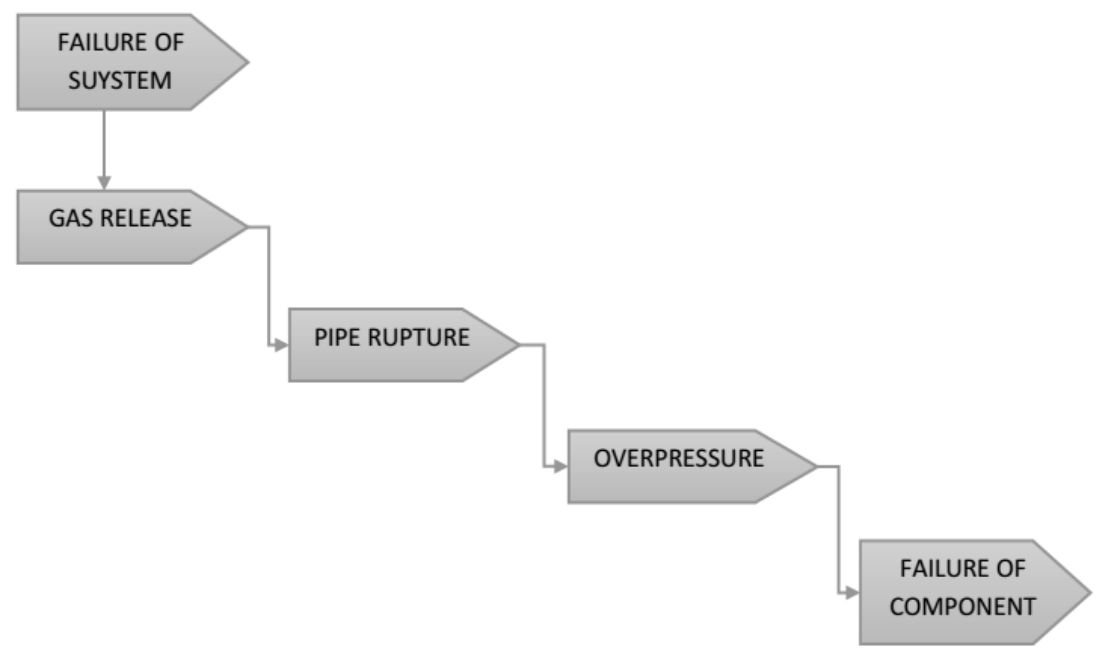

Figure 3: Failure Scenario

Assessment of Frequency of Gas Release is calculated according to three kinds of assumption leak category. The calculating frequency of failure for system, the first known frequency value of failure for each component supporting the system is based on Failure Frequency Guidance, Leak category values taken are $<10 \mathrm{~mm}, 10-50 \mathrm{~mm}$ and $>50 \mathrm{~mm}$ [6]. And value of failure rate for components based on the failure frequency guidance can be seen in Table 3 .

Table 3: Failure Rate Frequency of Components

\begin{tabular}{|c|c|c|c|c|}
\hline \multicolumn{5}{|c|}{ Ball Valve (BV) } \\
\hline \multirow{2}{*}{ Type hole size } & \multirow{2}{*}{ Range Hole Diameter } & \multicolumn{3}{|c|}{ Valve Diameter } \\
\hline & & $1 / 2 "$ & $1 ”$ & $3 "$ \\
\hline Small & $<10 \mathrm{~mm}$ & $1.837 \mathrm{E}-05$ & $1.841 \mathrm{E}-05$ & 1.279E-05 \\
\hline Medium & $10-50 \mathrm{~mm}$ & $0.0 \mathrm{E}+00$ & $0.0 \mathrm{E}+00$ & $7.459 \mathrm{E}-06$ \\
\hline Large & $>50 \mathrm{~mm}$ & $0.0 \mathrm{E}+00$ & $0.0 \mathrm{E}+00$ & $0.0 \mathrm{E}+00$ \\
\hline \multicolumn{5}{|c|}{ Pressure Relieve Valve (PRV) } \\
\hline \multirow[t]{2}{*}{ Type hole size } & Range Hole Diameter & \multicolumn{3}{|c|}{ Valve Diameter } \\
\hline & & $1 / 2 ”$ & $1 ”$ & $3 ”$ \\
\hline
\end{tabular}




\begin{tabular}{|c|c|c|c|c|}
\hline Small & $<10 \mathrm{~mm}$ & $7.507 \mathrm{E}-05$ & $7.515 \mathrm{E}-05$ & $5.447 \mathrm{E}-05$ \\
\hline Medium & $10-50 \mathrm{~mm}$ & $0.0 \mathrm{E}+00$ & $0.0 \mathrm{E}+00$ & $2.140 \mathrm{E}-05$ \\
\hline Large & $>50 \mathrm{~mm}$ & $0.0 \mathrm{E}+00$ & $0.0 \mathrm{E}+00$ & $0.0 \mathrm{E}+00$ \\
\hline \multicolumn{5}{|c|}{ Drain Valve (DV) } \\
\hline Type hole size & Range Hole Diameter & $1 / 2 "$ & $1 ”$ & $3 "$ \\
\cline { 3 - 5 } & & $1.837 \mathrm{E}-05$ & $1.841 \mathrm{E}-05$ & $1.279 \mathrm{E}-05$ \\
\hline Small & $<10 \mathrm{~mm}$ & $0.0 \mathrm{E}+00$ & $0.0 \mathrm{E}+00$ & $7.459 \mathrm{E}-06$ \\
\hline Medium & $10-50 \mathrm{~mm}$ & $0.0 \mathrm{E}+00$ & $0.0 \mathrm{E}+00$ & $0.0 \mathrm{E}+00$ \\
\hline Large & $>50 \mathrm{~mm}$ & \multicolumn{3}{c|}{ Valve Diameter } \\
\hline \multicolumn{5}{|c|}{ Master Valve (MV) } \\
\hline Type hole size & Range Hole Diameter & $1 / 2 "$ & $3 "$ \\
\cline { 2 - 5 } & $<10 \mathrm{~mm}$ & $1.837 \mathrm{E}-05$ & $1.841 \mathrm{E}-05$ & $1.279 \mathrm{E}-05$ \\
\hline Small & $10-50 \mathrm{~mm}$ & $0.0 \mathrm{E}+00$ & $0.0 \mathrm{E}+00$ & $7.459 \mathrm{E}-06$ \\
\hline Medium & $>50 \mathrm{~mm}$ & $0.0 \mathrm{E}+00$ & $0.0 \mathrm{E}+00$ & $0.0 \mathrm{E}+00$ \\
\hline Large &
\end{tabular}

In analysing the gas release frequency is used Fault Tree Analysis (FTA) according to system failure scenario. And all the failure frequency values for all components of this node are included in the FTA analysis (See Figure 4) and the result is shown in Table 4.

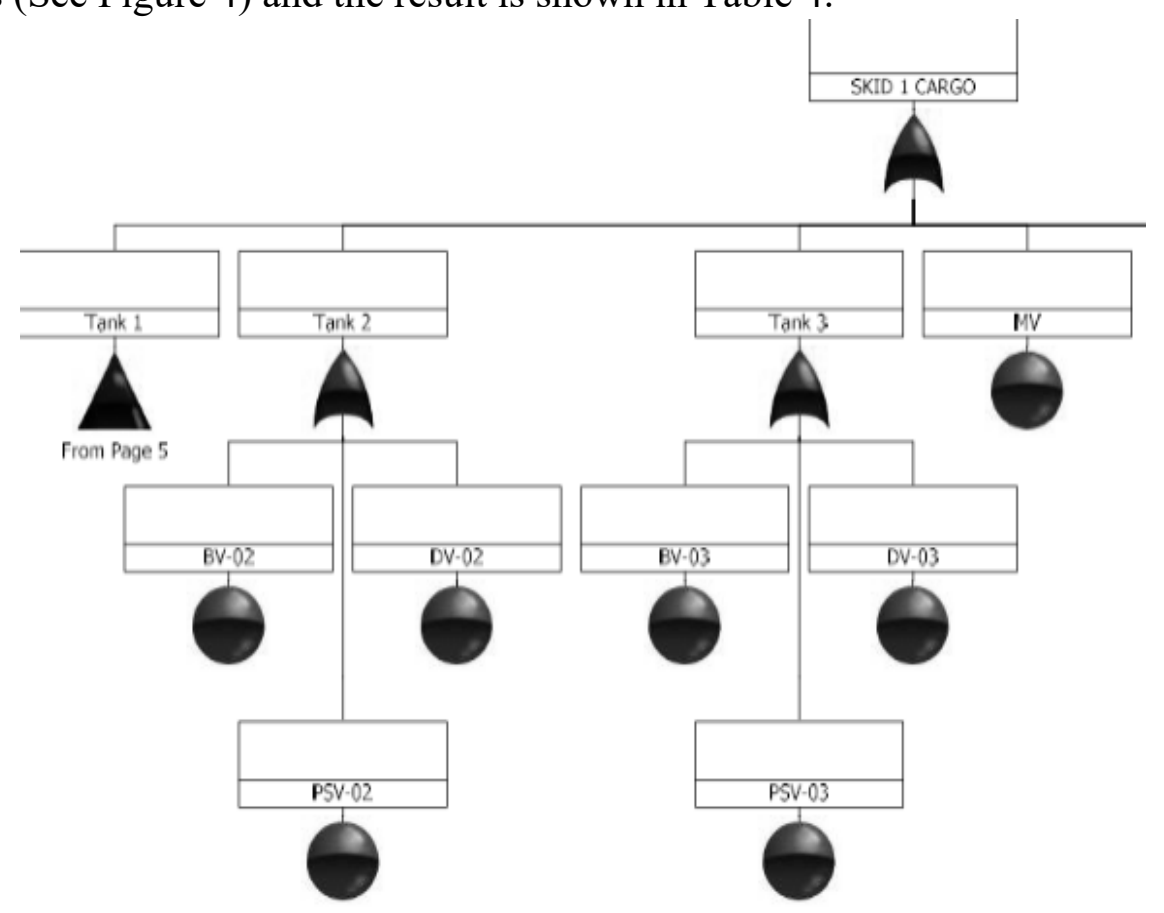

Figure 4: FTA for Gas Release Frequencies

Table 4: Gas Release Frequency in Different Leak Category

\begin{tabular}{|c|c|c|c|c|c|}
\hline No. & Node. & Scenario & \multicolumn{3}{|c|}{ Gas Release Frequency } \\
\cline { 3 - 5 } & & $<10 \mathrm{~mm}$ & $10-50 \mathrm{~mm}$ & $>50 \mathrm{~mm}$ \\
\hline 1. & $\begin{array}{c}\text { High Pressure } \\
\text { Pipe }\end{array}$ & Gas release & $2.400 \mathrm{E}-5$ & $1.836 \mathrm{E}-5$ & $1.278 \mathrm{E}-5$ \\
\hline
\end{tabular}


And the next step is, determine of gas release frequency due to component failure. For a gas release condition, the researcher assumes the gas released in two conditions ie gas released can burn immediately if there is a source of fire (Immediate Ignition) and the released gas does not cause the first burning of gas (No-Immediate Ignition). Based on these conditions there are several possible risks that may occur, as follows:

- Flash fire is a condition where lightning occurs, since the event generally takes place in the range of 0-5 seconds, this phenomenon is like explosion-turbulence of flammable mixture and air causing a short fire, depending on the turbulence and the magnitude of the vapour cloud [7].

- Gas Explosion is the event of an explosion due to the leaking of the pressure vessel due to exposure to heat from the outside or in a vessel where the vessel contains a pressurized liquid at a temperature above the boiling point of said compressed liquid [7]

- Gas Dispersion is the event of the release of natural gas in the gas phase which the release speed is small either continuously or not due to leakage of pipes or components in a facility without the existence of fire source [7].

The frequency of that risk is calculated using Event Tree Analysis (ETA) which is shown in Figure. 5 and the result of calculation for all leak category can be seen in Table 5 .

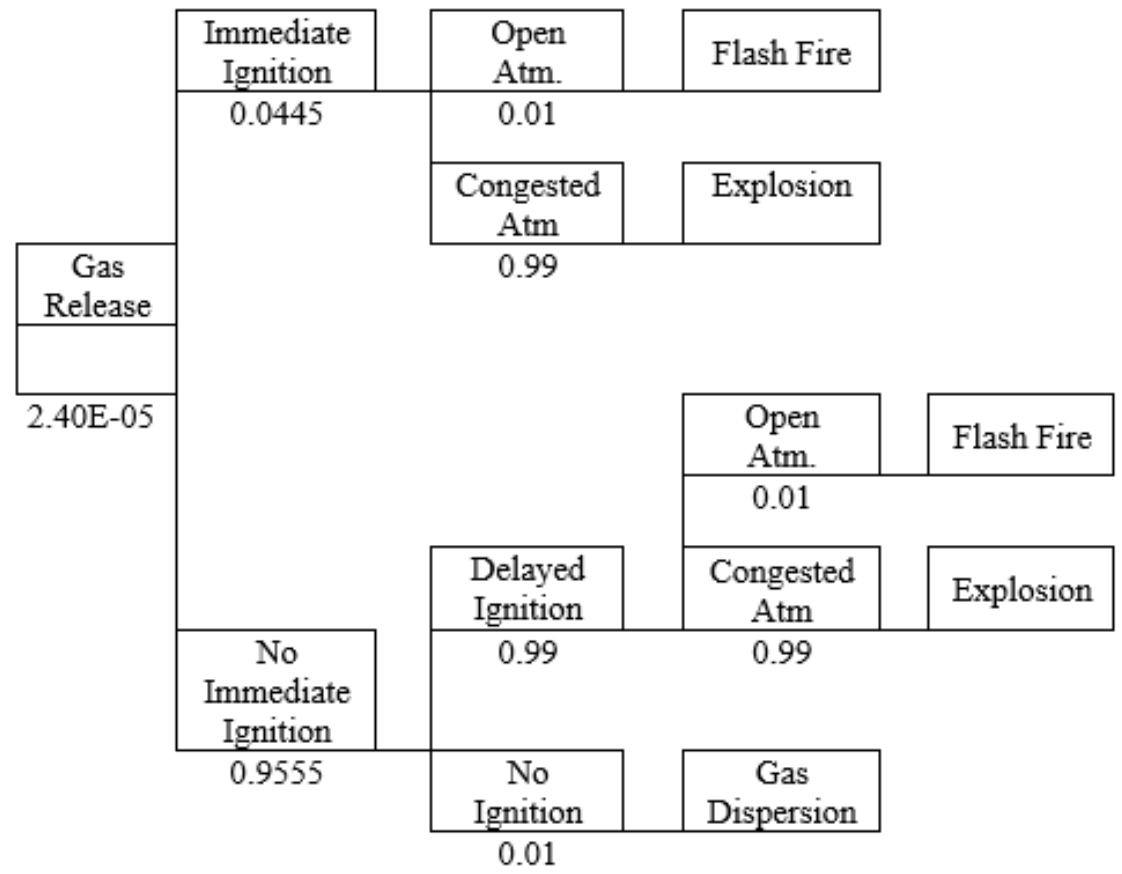

Figure 5: Event Tree Analysis

Table 5: Incident frequency Due to gas Released

\begin{tabular}{|c|c|c|c|c|c|c|}
\hline \multirow{2}{*}{$\begin{array}{c}\text { Hole } \\
\text { Category. } \\
(\mathrm{mm})\end{array}$} & Gas Release & \multicolumn{2}{|c|}{ Immediate Ignition } & \multicolumn{3}{c|}{ No Immediate Ignition } \\
\cline { 3 - 7 } & Flash Fire & Explosion & Flash Fire & Explosion & Gas Dispersion \\
\hline$<10$ & $2.400 \mathrm{E}-5$ & $1.07 \mathrm{E}-8$ & $1.06 \mathrm{E}-6$ & $2.27 \mathrm{E}-7$ & $2.25 \mathrm{E}-5$ & $2.29 \mathrm{E}-7$ \\
\hline $10-50$ & $1.836 \mathrm{E}-5$ & $8.17 \mathrm{E}-9$ & $8.09 \mathrm{E}-7$ & $1.74 \mathrm{E}-7$ & $1.72 \mathrm{E}-5$ & $1.75 \mathrm{E}-7$ \\
\hline$>50$ & $1.278 \mathrm{E}-5$ & $5.69 \mathrm{E}-9$ & $5.63 \mathrm{E}-7$ & $1.21 \mathrm{E}-7$ & $1.20 \mathrm{E}-5$ & $1.22 \mathrm{E}-7$ \\
\hline
\end{tabular}




\subsection{Consequences Analysis}

The consequence of system failure was analysed using Fire Spread Software. The fire spread simulation gives the values of gas release effect. Besides that, the radius of flash fire and gas explosion are also simulated. The results of simulation are shown in Figure 6.

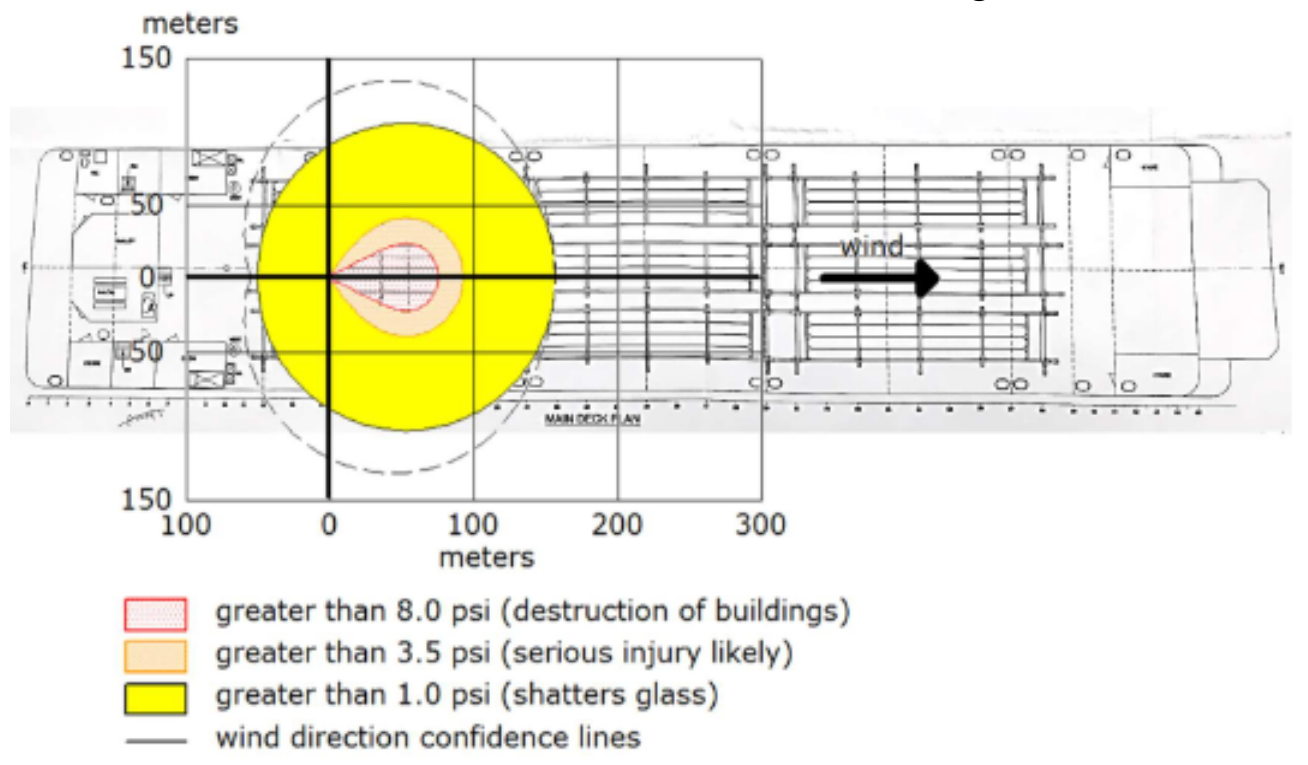

Figure 6: Simulation of Gas Release

Based on Figure.6 the consequence fatality according to fire spread simulation shown that the fire spread with the radius of 30 meter. The distance between CNG tank and accommodation space is less than 30 meters, then it can be concluded that all crews (12 persons) impacted to the fire damage. The table of frequency relations and consequences for each pipe leak diameter range can be seen in Table 6 below.

Table 6: Gas Release Frequency in Different Leak Range with effect (Consequency)

\begin{tabular}{|c|c|c|c|c|}
\hline \multirow[b]{2}{*}{$\begin{array}{l}\text { Hole D } \\
(\mathrm{mm})\end{array}$} & \multicolumn{3}{|c|}{ Frequencies } & \multirow{2}{*}{$\begin{array}{c}\text { Consequence } \\
\text { Fatality }(\mathrm{N})\end{array}$} \\
\hline & $\begin{array}{l}\text { Pressure } \\
\text { (psi) }\end{array}$ & Severity level & $\begin{array}{l}\text { Threat zone } \\
\text { range }(\mathrm{m})\end{array}$ & \\
\hline \multirow{3}{*}{$<10$} & 8.0 & $\begin{array}{l}\text { Destruction of of } \\
\text { accomodation area (ship) }\end{array}$ & $\begin{array}{l}0-70 \mathrm{~m} \text { from } \\
\text { accident point }\end{array}$ & 12 \\
\hline & 3.5 & Serious injury likely & $\begin{array}{c}0-80 \mathrm{~m} \text { from } \\
\text { accident point }\end{array}$ & 12 \\
\hline & 1 & Injury & $\begin{array}{l}\text { Radius } 0-200 \mathrm{~m} \\
\text { from accident } \\
\text { point }\end{array}$ & 12 \\
\hline \multirow{3}{*}{$10-50$} & 8.0 & $\begin{array}{l}\text { Destruction of of } \\
\text { accomodation area (ship) }\end{array}$ & $\begin{array}{l}\text { 0-31 m from } \\
\text { accident point }\end{array}$ & 12 \\
\hline & 3.5 & Serious injury likely & $\begin{array}{l}0-38 \mathrm{~m} \text { from } \\
\text { accident point }\end{array}$ & 12 \\
\hline & 1 & Injury & $\begin{array}{l}\text { Radius } 0-84 \mathrm{~m} \\
\text { from accident } \\
\text { point }\end{array}$ & 12 \\
\hline
\end{tabular}




\begin{tabular}{|c|c|l|c|c|}
\hline \multirow{3}{*}{$>50$} & 8.0 & $\begin{array}{l}\text { Destruction of of } \\
\text { accomodation area (ship) }\end{array}$ & $\begin{array}{c}0-36 \mathrm{~m} \text { from } \\
\text { accident point }\end{array}$ & 12 \\
\cline { 2 - 5 } & 3.5 & Serious injury likely & $\begin{array}{c}0-44 \mathrm{~m} \text { from } \\
\text { accident point }\end{array}$ & 12 \\
\cline { 2 - 5 } & 1 & $\begin{array}{c}\text { Radius 0-98 } \mathrm{m} \\
\text { from accident } \\
\text { point }\end{array}$ & 12 \\
\hline
\end{tabular}

\subsection{Risk Evaluation}

After obtaining the result of frequency calculation and consequence, risk evaluation by using f-N curve either on Immediate ignition condition or no-immediate ignition. The results can be seen in the figure below (Figure 7 to Figure 11).

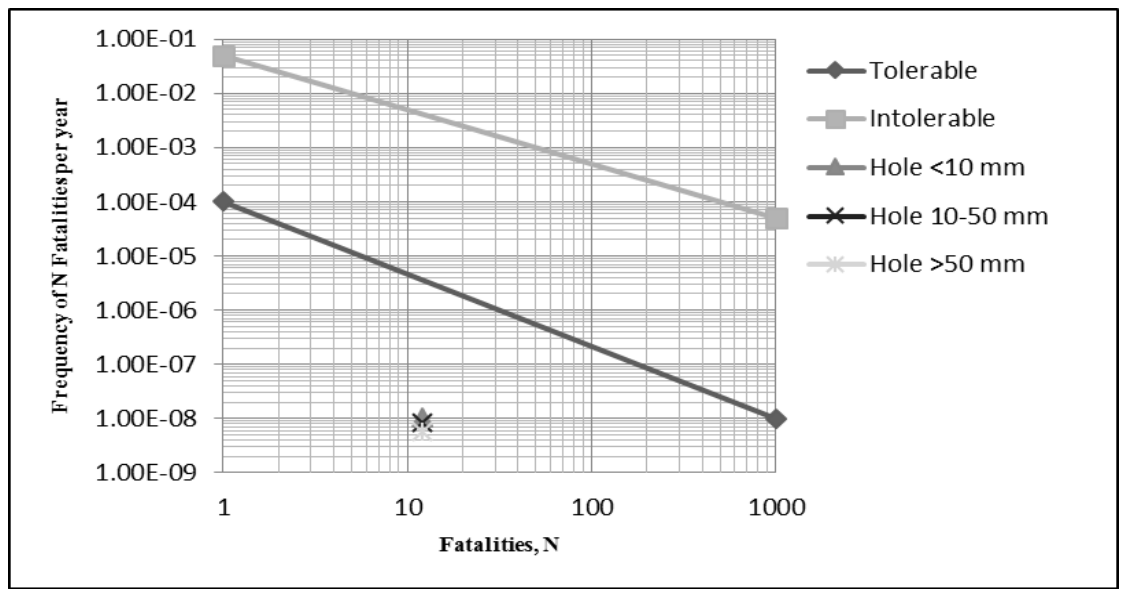

Figure 7: Simulation Result of Flash Fire (Immediate Ignition)

From Figure 7, shown that all kinds of leak category are in tolerable zone. It can be concluded that the installation design can be accepted as safety installation to flash fire in immediate ignition condition.

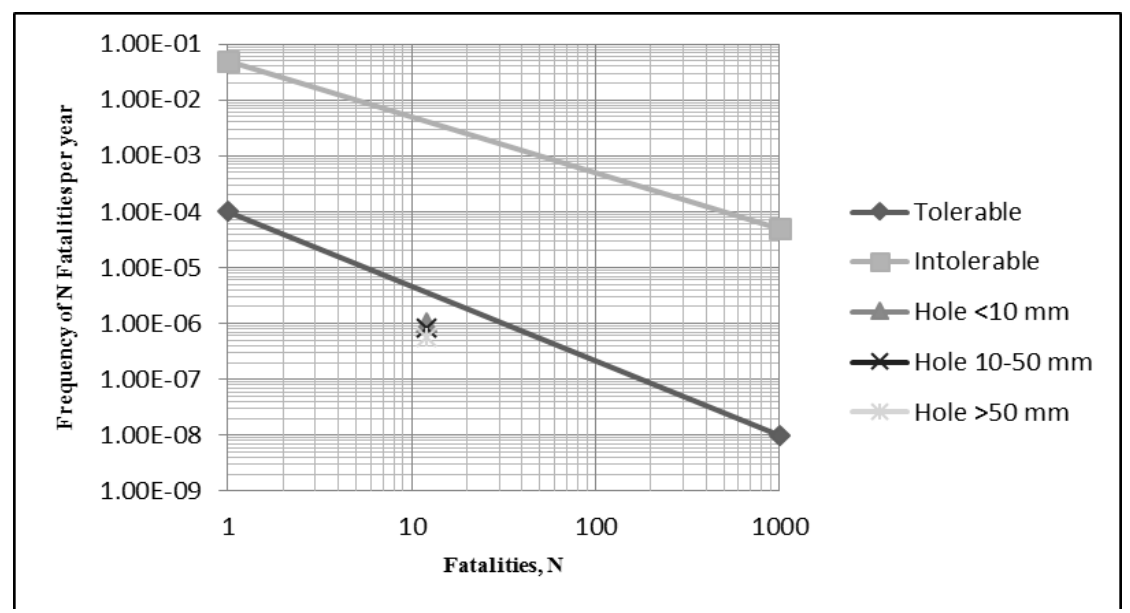

Figure 8: Simulation Result of Gas Explosion (Immediate Ignition) 
On the other hand, in Figure 8, the f-N relation of risk assessment according with consequency is Gas Explosion for Immediate ignition condition is tolerable level. It can be concluded that the risk level is still in safe zone.

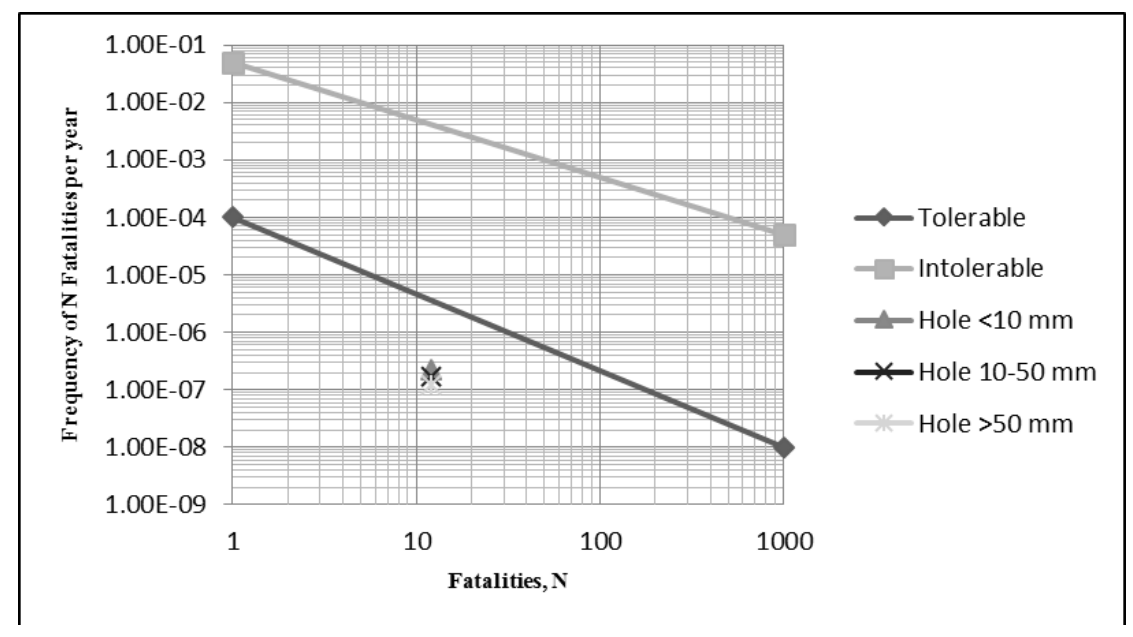

Figure 9: Simulation Result of Flash Fire (No-Immediate Ignition)

From Figure 9, shown that all kinds of diameter ranges are in tolerable zone. It can be concluded that the installation design can be accepted as safety installation to flash fire in No-immediate ignition condition.

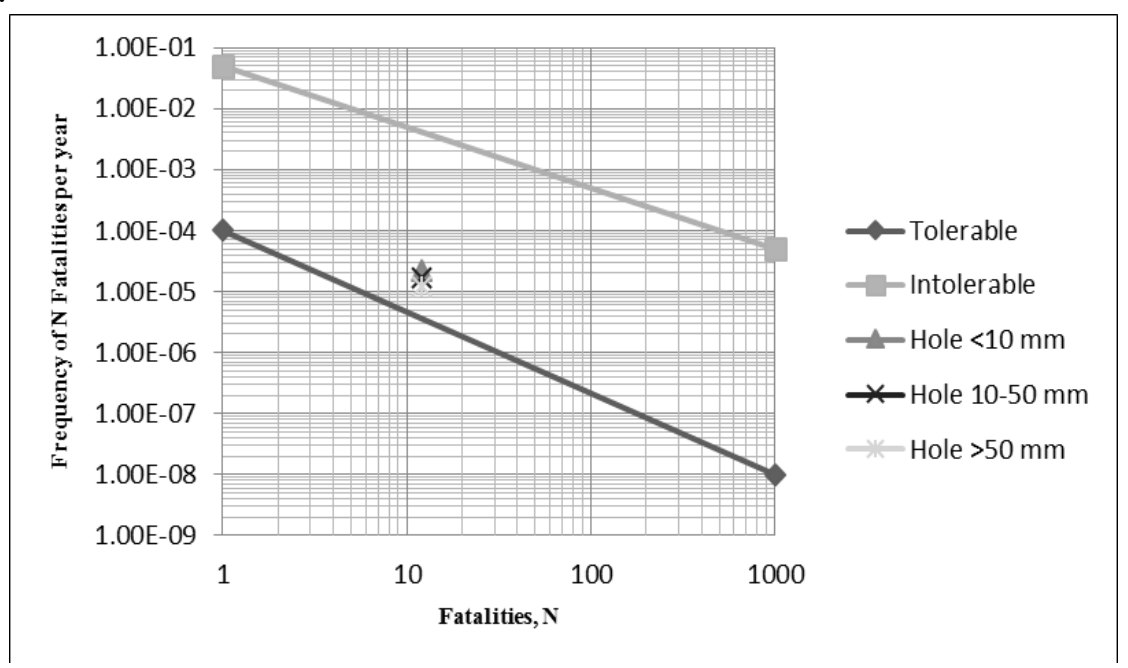

Figure 10: Simulation Result of Gas Explosion (No-Immediate Ignition)

On the other hand, in Figure 9, the f-N relation of risk assessment according with consequence is Gas Explosion for No-immediate ignition condition is in ALARP level. It can be concluded that the risk level is still in safe zone. However, it needs some mitigation to increase the safety level among the crews and reduce the risk level. 


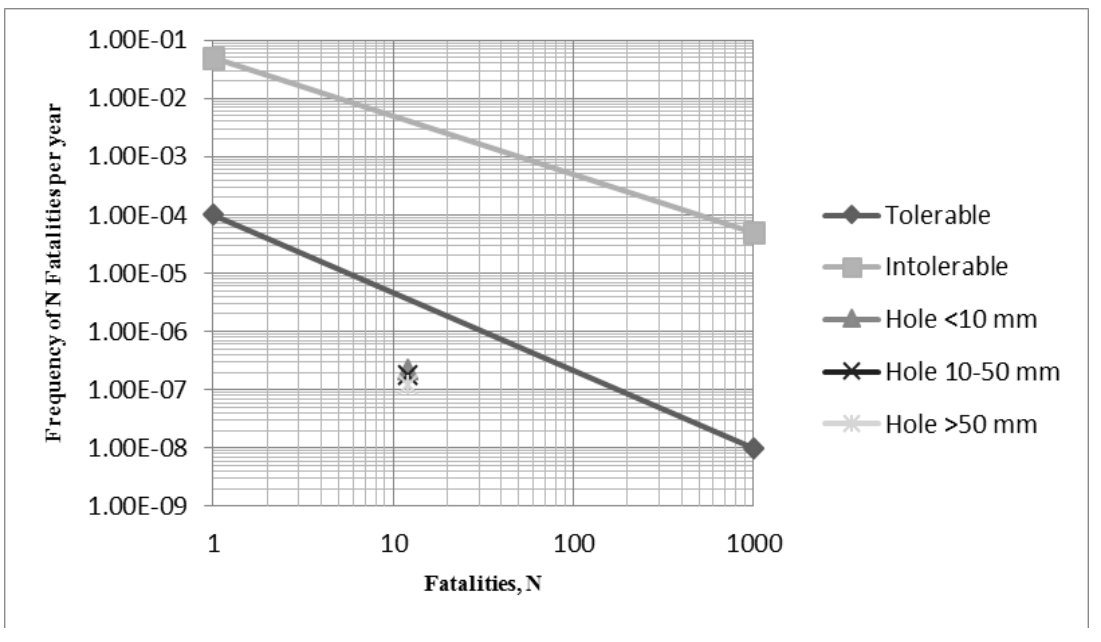

Figure 11: Simulation Result of Gas Dispersion (No-Immediate Ignition)

From Figure 11 shown that all kinds of leak category are in tolerable zone. It can be concluded that the installation design can be accepted as safety installation to Gas Dispersion in No-immediate ignition condition.

\section{Mitigation and Discussion}

From the results of risk evaluation for two conditions is immediate ignition and No-immediate ignition for each leak categories it can be happen is flash fire and in tolerable level with failure rate frequency is $1.07 \mathrm{E}-8$ per year. This indicates that the frequency of gas release resulting in flash fires in both conditions is very small when compared to the age of LCT ships that is only 25 years. For comparison values between leakage categories and leakage frequency in two ignition conditions for all leak categories.

The other risk simulation is gas dispersion under No-Immediate Ignition conditions for various leak categories are at tolerable levels with a frequency value of 1.22E-07 per Year. This indicates the occurrence of gas dispersion is very unlikely to occur. Furthermore, for the type of gas explosion in two conditions that is Immediate ignition and no-immediate ignition. the second result of the gas explosion consequence analysis for both conditions is obtained which is different for immediate level of risk at acceptable level while in the no-immediate ignition condition is at ALARP level (see figure 9).

This difference is caused due to the gas explosion conditions in No-Immediate ignition, that the gas occurs gas collection significantly.

The ALARP condition to be still at a safe level but some things of concern must be taken to cope or reduce the severity of the impact of the gas explosion, as follows:

- Wall protection in each tank to prevent the fire spread to the accommodation area and crew.

- Safety device in each tank to detect, give alarm and shutdown the system when overpressure happened can increase early awareness of the risks that can occur.

- All equipment on board must be explosion type. to withstand the explosion the electrical equipment remains in good condition and does not add to the cause of the fire.

- Avoid static electricity that can be a source of fire in gas

- Installing a sufficient barrier between the tank and the engine room space (are to be separated with sufficient of distance)

- Monitoring controls are carried out at any time against the gas conditions in the tank so that no overheating, overpressure occurs. 
- As well as the safety provisions for other gas carriers shall be met, especially in the early stages of the design.

Mitigation can reduce the impact of risks that can occur, the severity of the risk that occurs can be reduced. Because the risk can not be eliminated but can only be reduced.

\section{Conclussion}

Based on fire risk assessment of LCT CNG Carrier caused by gas release can be divided into 2 conditions which are immediate ignition and no immediate ignition. The hazard caused by fire are flash fire, gas explosion, and gas dispersion.

The fire risk assessment can be concluded that:

- The consequence of Flash Fire on immediate ignition in tolerable level with a maximum failure rate of $1.07 \mathrm{E}-08$ per year. The condition is very small when compared to the age of LCT ship is maximum only 25 years.

- Gas Dispersion in No-Immediate Ignition is in Tolerable zone with gas release frequency at leak category $>50 \mathrm{~mm}$ is small ie $1.22 \mathrm{E}-7$.

- Gas Explosion in Immediate Ignition is in tolerable level.

- Gas Explosion in No-Immediate Ignition is in ALARP level which can be interpreted as safe zone. However, it needs some mitigation plan to prevent the risk as described above.

\section{References}

[1] The World Fatchbook, Country Comparison: Natural Gas-Proved Reserves. (Januari 2017)

[2] https://kumparan.com/@kumparannews/kementerian-esdm,2017

[3] BKI Reference note of Risk Assessment Application for The Marine and Offshore Oil and Gas Industries , Edisi

[4] UK HSE Offshore: f-N Curve Plot Standard, London, Uited Kingdom, 1991

[5] BS IEC 61882:2001, Hazard and operability studies (HAZOP studies). Application guide

[6] Det Norske Veritas AS: Failure frequency Guidance, Process equipment leak frequency data for use in QRA.

[7] M. Munir, Artana,K.B, Dinariyana A.A.B Fire Risk Assessment of Gas Liquefaction Process on FLNG, The 5th Basic Science International Conference (BaSIC 2015). 